\title{
Subjective Burden on Family Carers of Hemodialysis Patients
}

\author{
Magda M. Bayoumi \\ Medical Surgical Nursing, Nursing College, King Khalid University, Abha, Saudi Arabia \\ Email: mbayeome@kku.edu.sa
}

Received 4 April 2014; revised 3 May 2014; accepted 2 June 2014

Copyright (C) 2014 by author and Scientific Research Publishing Inc.

This work is licensed under the Creative Commons Attribution International License (CC BY). http://creativecommons.org/licenses/by/4.0/

(c) (;) Open Access

\section{Abstract}

Background: Hemodialysis (HD) is an important objective burden (task) on patient with end stage renal disease (ESRD) and the caregiver has a subjective burden which contributes to lifestyle changes, which result in depression, anxiety declining physical health, social isolation and financial strain. Aim: To evaluate the subjective burden on family caregiver who cares patient on maintenance hemodialysis therapy. Methods: Fifty main family caregivers for each patient on HD and the instrument were used by Caregiver Burden Interview (CBI) completed by caregiver as a major of subjective response to care giving. Results: The present study findings demonstrated that main age of caregiver was $40(11.0)$ years, two thirds of females, and they were mostly married (78.0\%) with children. The total family caregiver burden reported was $43.3(21.7)$, role strain $50.0(25.4)$ and the personal strain 39.5 (19.7). The total caregivers' burden significantly positively correlated with the patients' age $(r=0.461)$ and negatively correlated with patients' level of education $(r=$ -0.290). Moreover the role strain, personal strain and total caregiver burden scores were statistically and significantly negatively correlated with their age $(r=-0.444)$ and level of education $(r=$ -0.416) and the total burden scores were ranked as moderately to severely burdened all family caregivers. Conclusion: Caregivers' appraisal, coping strategies, interpersonal relationship issues, and social support would need to be considered for caregivers of patients maintained on HD.

\section{Keywords}

Dialysis, Burden, Family Caregiver, Saudi Arabia

\section{Introduction}

Dialysis patients are at increasing risk of physical, cognitive and emotional impairment related to many factors: such as length of dialysis duration, dialysis populations' ages, high prevalence of cardiovascular risk factors and 
multiple metabolic disturbances [1]. Accordingly, the mainstay of therapy for end stage renal disease (ESRD) hemodialysis (HD) places a burden in terms of the need for ongoing medical intervention and treatment time [2]. It is essential to properly control the symptoms and complications of ESRD and work towards the full rehabilitation of the renal patient [3]. Related to burden of HD described, a number of physical symptoms that they found were stressful, feeling sick, fatigue, insomnia, heart problems, and decreased mobility. The theme of stressors is composing of participants' experiences of physical, psychological, and logistical stressors. However, the stressors were defined by patients' experience, responses and preparatory behaviors to those stressors, regrets and advice [4]. As well, most chronically ill patients are cared for by an informal support system comprised of family members. Moreover caring for patients with chronic and disabling disease is associated with the caregivers' experiencing physical and psychological distress, limitations to their personal and social activities, and financial burden [5]. Especially the experience of a wife caregiver has been described as a mixture of anger, helplessness, guilt and isolation and was deemed to have lost freedom, because they had relinquished recreational and social activities [6].

The patients, who are physically and/or mentally unable to provide the necessary treatment for themselves, require a caregiver to assume major responsibility for their treatment [7], whereas the burden of family caregivers leads to negative consequences not only for themselves but also for patients, other family members, and health care system. Moreover for caregivers, burden negatively affects caregiver's physical, emotional, and economic status [8].

Family caregiver is the most important person who cares for patient. However, when care is provided for a long time, he/she may experience the burden [9]. This in turn may result in a more negative impact on the emotional and social aspects of caregivers' lives [10].

In fact, those families which maintain primary responsibility for the care of hemodialysis patients are not well understood. Although recent studies have shown that some family members find caregiving to be burden and stressful, while others derive self satisfaction for caregiving, there is no study evaluating the subjective burden on family caregiver of hemodialysis patients in the Kingdom of Saudi Arabia. Therefore this study aimed to evaluate the subjective burden on family caregiver who cares patient on maintenance hemodialysis therapy.

\section{Materials and Methods}

\subsection{Design and Study Population}

We conducted a cross-sectional survey of 50 caregivers for their patients enrolled in the Security Forces Hospital, Riyadh, Saudi Arabia. To be eligible, a patient should have been on maintenance hemodialysis therapy for more than 3 months, regardless of age or sex. A caregiver is defined in this study as the family member who provides the physical help and support to the patient and takes the responsibility of ensuring patient's compliance with physician's dietary instructions, pharmacological prescriptions, and the dialysis routine.

\subsection{Questionnaires and Data Collection}

Caregivers' Background: age, sex, work status, marital status, level of education, health problem and other burden on family caregiver such as other patient in family, financial burden related to needs of caregivers' life or health problems.

\subsubsection{Caregiver Burden Interview}

This consisted of a 22-item self-report instrument; the Caregiver Burden Interview (CBI) was completed by caregivers as a measure of subjective response to caregiving. The instrument was translated into Arabic language. Final form was reached by consensus of experts. It was tested by a pilot study to investigate the feasibility and clarity of the tool and its translation. The dimensions of the subjective burden tool have been determined by Zarit [11]. The scales represent the dimensions of personal strain and role strain.

\subsubsection{Scoring}

The burden interview is scored by summing the responses of the individual items. Higher scores indicate greater caregiver distress. The level of subjective burden was determined according to the following scoring: (0 - 20) little to no burden, (21 - 40) Mild to Moderate, (41 - 60) Moderate to severe burden and (61 - 88) Sever burden. 


\subsection{Preparatory Phase}

During this phase, the research was developing the research tools. Certain of these were obtained from authors through E-mail. Then started the process of translation, and review by experts for finalization. It has also involved preparation of the settings for the study.

\subsection{Field Work}

Personal interviews with the caregivers were scheduled at study settings. The researcher started to take an appointment was set with the caregiver at the hospital, at home, or at the workplace. The time for filling the questionnaire sheet from the caregiver took 10 - 15 minutes.

\subsection{Limitation of the Study}

The tool was lengthy, and sometimes needed more than one meeting with the caregiver. Moreover, an appointment with main caregiver may canceled regarding to caregiver time and re-scheduled again.

\subsection{Ethical Consideration}

The researcher met with director of the dialysis unit and explained the aim and process of the study. Caregiver's verbal consents were obtained. Complete confidentiality of any obtained information was ensured. The researcher has also assured the administration that the conduction of the study will not affect the work in the study settings.

\subsection{Statistical Analysis}

The SPSS version 18.0 statistical software packages for statistical analysis. Data were presented using descriptive statistics in the form of frequencies and percentages for qualitative variables, and means and standard deviations for quantitative variables. For multiple group comparisons of quantitative data, one-way analysis of variance test (ANOVA) was used. Pearson correlation analysis was used for assessment of the inter-relationships among quantitative variables. Multiple stepwise backward regression analysis was used, and analysis of variance for the full regression models were done. Statistical significance was considered at p-value $<0.05$.

\section{Results}

The characteristics of caregivers in the sample are displayed in Table 1, the most of caregivers were female, Unemployed/housewife, with Basic/intermediate level of education. Moreover mostly married, and have children, with an age $52.0 \%$ more the 40 of years on average. Not all caregiver were enjoying a perfect health, since more half of them did report having health problems.

Table 2 demonstrates the scores of caregivers' burden and its components. Significant variation in caregivers burden was evident with a total score ranging from (41 - 60) Moderate to severe burden, When broken down to reflect levels of severity, the mean burden scores $(43.3+21.7)$ were ranked as moderate to severe burden on family caregiver.

Table 3: The correlation between caregivers' burden scores and patients' age, duration of illness and level of education. It points to statistically significant positive correlation between total caregivers' burden score and patients' age. Conversely, total caregivers' burden score was negatively and significantly correlated to patients' level of education $(r=-0.290)$, and positively and significantly correlated with patients' age $(r=0.461)$.

Table 4: Correlations between caregivers' burden scores and their age, education, and patient's duration of illness, it shows statistically significant negative correlation between total caregivers' burden score and it components to and caregivers' age and level of education.

\section{Discussion}

Dialysis therapy is an important objective burden (task) associated with care of patient with ESRD. Science many patients on HD require a caregiver to take care of them, with their daily living and medical needs, alternatively, objective caregiver burden, on one hand, is comprised of those tasks or burden required to care for the 
Table 1. The caregivers’ personal characteristics.

\begin{tabular}{|c|c|c|}
\hline & \multicolumn{2}{|c|}{ Hemodialysis $(n=50)$} \\
\hline & No. & $\%$ \\
\hline \multicolumn{3}{|l|}{ Age (years): } \\
\hline$<30$ & 10 & 20.0 \\
\hline $30-40$ & 14 & 28.0 \\
\hline $40+$ & 26 & 52.0 \\
\hline \multicolumn{3}{|l|}{ Range } \\
\hline Mean (SD) & \multicolumn{2}{|c|}{$40.6(11.0)$} \\
\hline \multicolumn{3}{|l|}{ Gender: } \\
\hline Male & 15 & 30.0 \\
\hline Female & 35 & 70.0 \\
\hline \multicolumn{3}{|l|}{ Relation to patient: } \\
\hline Spouse/children & 31 & 62.0 \\
\hline Others & 19 & 38.0 \\
\hline \multicolumn{3}{|l|}{ Education: } \\
\hline Illiterate & 10 & 20.0 \\
\hline Basic/intermediate & 22 & 44.0 \\
\hline High & 18 & 36.0 \\
\hline \multicolumn{3}{|l|}{ Marital status: } \\
\hline Married & 39 & 78.0 \\
\hline Unmarried & 11 & 22.0 \\
\hline \multicolumn{3}{|l|}{ Have children: } \\
\hline No & 8 & 16.0 \\
\hline Yes & 42 & 84.0 \\
\hline \multicolumn{3}{|l|}{ Job: } \\
\hline Unemployed/housewife & 30 & 60.0 \\
\hline Working & 20 & 40.0 \\
\hline \multicolumn{3}{|l|}{ Have health problems: } \\
\hline No & 18 & 36.0 \\
\hline Yes & 32 & 64.0 \\
\hline Dialysis duration (months): Mean (SD) & \multicolumn{2}{|c|}{$75.1(62.8)$} \\
\hline
\end{tabular}

Table 2. The caregivers' burden scores.

\begin{tabular}{lcc}
\hline & \multicolumn{2}{c}{ Hemodialysis $(\mathrm{n}=50)$} \\
\cline { 2 - 3 } & Mean & SD \\
\hline Caregiver burden: & 50.0 & \\
Role & 39.5 & 25.4 \\
Personal & 43.3 & 19.7 \\
Total & 1.6 & 21.7 \\
Overall & 1.5 \\
\hline
\end{tabular}


Table 3. Correlations between caregivers’ burden scores and patients' age, duration of illness, and level of education.

\begin{tabular}{lccc}
\hline & \multicolumn{3}{c}{ Pearson correlation coefficients } \\
\cline { 2 - 4 } & \multicolumn{3}{c}{ Hemodialysis $(\mathrm{n}=50)$} \\
\cline { 2 - 4 } & Age & Duration & Education $^{\#}$ \\
\hline Caregiver burden: & & \\
Overall & 0.25 & 0.208 & -0.22 \\
Total & $0.461^{* *}$ & 0.206 & $-0.290^{*}$ \\
\hline
\end{tabular}

"Statistically significant at $\mathrm{p}<0.05 ;{ }^{* *}$ Statistically significant at $\mathrm{p}<0.01$; ${ }^{*}$ Spearman rank correlation.

Table 4. Correlations between caregivers' burden scores and their age, education, and patient's duration of illness.

\begin{tabular}{lccc} 
& \multicolumn{3}{c}{ Pearson correlation coefficients } \\
\cline { 2 - 4 } & \multicolumn{3}{c}{ Hemodialysis $(\mathrm{n}=50)$} \\
\cline { 2 - 4 } & & Duration & Education $^{\#}$ \\
\hline Caregiver burden: & $-0.386^{* *}$ & 0.099 & $-0.334^{*}$ \\
Role & $-0.473^{* *}$ & 0.136 & $-0.458^{* *}$ \\
Personal & $-0.444^{* *}$ & 0.124 & $-0.416^{* *}$ \\
Total & $-0.322^{*}$ & 0.132 & $-0.390^{* *}$ \\
Overall & & & \\
\hline
\end{tabular}

*Statistically significant at $\mathrm{p}<0.05 ;{ }^{* *}$ Statistically significant at $\mathrm{p}<0.01$; ${ }^{*}$ Spearman rank correlation.

client. On the other hand, subjective burden indicates the extent to which the caregiver "minds" performing these tasks [12].

Belasco and Sesso, studied the burden on family caregiver and found the majority of caregivers were women (84\%), married (66\%), with a mean age of 46 years, and of low socioeconomic level. Their main types of relationship with patients were wives (38\%) and sons or daughters (27\%) [13]. Similarly, in the study conducted by Wicks et al., they have reported that the majority of caregivers were spouses (62\%), females (76\%), employed (67\%), and lived with the patient (79\%). The mean length of dialysis was $18.6 \pm 18.2$ months (range 5 to 82 months) for patients receiving renal replacement therapy. Which are close to that of the studied patients in this study. But as regards the unemployed caregivers in the present study were $(60 \%)$ caring for hemodialysis patients for mean length of dialysis duration $75.1 \pm 62.8$ months [14].

Other study done by Beanlands et al., were presented that caregivers role of patients on hemodialysis is very important and described specific caring tasks, including dialysis-related activities, management of diet, medications and symptoms in addition the personal caregivers shared a rich repertoire of caregiving abilities and activities that were often supported by a strong knowledge base [15]. However, the present study findings investigate perceived burden and correlates in family caregivers of hemodialysis patients, we found the caregivers remarked burden as moderate to severe similar to recent research reported that majority of the unpaid caregiver having extremely high perceptions of burden [16].

Moreover, the present study findings showed that is statistically significant positive correlation between total caregivers' burden score and patients' age. Conversely, Rioux et al. has reported that a relatively low global burden perceived by caregivers and patients undergoing nocturnal home hemodialysis [17]. Particularly the burden on family caregivers is important predictor may influenced with their level of education and age as showed in the study results, it shows statistically significant negative correlation between total caregivers' burden score and it components to caregivers' age and level of education. Conversely, Suri et al., reported no significant cor- 
relation among perceived caregiver burden and demographic factors including age, sex, race and level of education [16]. Moreover, the literature provides conflicting views regarding the significant predictor for caregiving by older people to lead to poor physical health, depression, and even increased mortality. However, younger caregivers must generally juggle work, their own family responsibilities, and sacrifices involving their social lives. Middle-aged caregivers typically worry about missed workdays, interruptions at work, taking leaves of absence, and reduced productivity [18] [19].

Arechabala et al. identified the depressive symptoms and degree of fatigue in caregivers of HD patients and found the primary caregivers were female spouses, with an average age of $50 \pm 16.1$ years. as well as the primary caregivers $(43.82 \%)$ had depressive symptoms [20]. A positive association $(r=0.43, p<0.001)$ statistically significant was found between self-perceived burden and the presence of depressive symptoms in patients. Caregiver burden contributes to lifestyle changes, which result in depression, anxiety, declining physical health, social isolation, and financial strain for the caregiver [21]-[23].

We found that caregivers of patient on hemodialysis reported increase burden of role strain more than personal strain. In addition, the two dimensions of personal strain and role strain are considered to reflect two important aspects of caregiving. Also, personal strain refers to how personally stressful the experience is, while overload due to role conflict constitutes role strain [24]. Because the caregiver burden contributes to lifestyle changes, which result in depression, anxiety, declining physical health, social isolation, and financial strain for the caregiver [21]-[23].

Finally, the empirical literature on family burden predictors requires more efforts to investigate how sociodemographic, clinical, and personality variables from patients and their relatives may combine to predict higher levels of burden. Plus the cultural differences, community values may play a role to identify the burden.

\section{Conclusion}

As the ESRD population in Saudi Arabia grows, the management of HD requires an ongoing commitment not only from the patient but also from the family when ongoing lifestyle adjustments become necessary as the disease complications. And there are minimal data regarding the identification of the aspects of caregiver burden, Caregiver's appraisal, coping strategies, interpersonal relationship issues, and social support would need to be considered for caregivers of patients maintained on HD. Nurses could render appropriate knowledge regarding hemodialysis and complications, how to help patients on hemodialysis to cope decrease burden on family caregiver and improve outcome of the patients' care. For further research, studies may investigate caregiver resources on decreasing burden, such as coping and social support especially in the eastern countries.

\section{Acknowledgements}

This research project was supported by Deanship of Scientific Research, King Khalid University. Saudi Arabia.

\section{References}

[1] Kalirao, P., Pederson, S., Foley, R.N., Kolste, A., Tupper, D., Zaun, D., Buot, V. and Murray, A.M. (2011) Cognitive Impairment in Peritoneal Dialysis Patients. American Journal of Kidney Diseases, 57, 612-620. http://dx.doi.org/10.1053/j.ajkd.2010.11.026

[2] Kimmel, P.L., Peterson, R.A., Weihs, K.L., Simmens, S.J., Boyle, D.H., Cruz, I., Umana, W.O., Alleyne, S. and Veis, J.H. (1995) Aspects of Quality of Life in Hemodialysis Patients. Journal of the American Society of Nephrology, 6, 1418-1426.

[3] Moreno, F.J.M., Lopez Gomez, M.J., Sanz-Guajardo, D., Jofre, R. and Valderrabano, F. (1996) Quality of Life in Dialysis Patients. A Spanish Multicentre Study. Nephrology Dialysis Transplantation, 11, 125-129. http://dx.doi.org/10.1093/ndt/11.supp2.125

[4] Harwood, L., Locking-Cusolito, H., Spittal, J., Wilson, B. and White, S. (2005) Preparing for Hemodialysis: Patient Stressors and Responses. Nephrology Nursing Journal, 32, 3.

[5] Choi, K.S. and Eun, Y. (2000) A Theory Construction on the Care Experience for Spouse of Patients with Chronic Illness. Journal of Korean Academic Nursing, 30, 122-136.

[6] Kumar, S., Matreja, P.S., Gupta, A.K., Singh, A. and Garg, P. (2012) To Assess the Quality of Life (QOL) of Caregivers and Patients Suffering from Chronic Obstructive Pulmonary Disease (COPD). Journal of Allergy and Therapy, 2155-6121. 
[7] Gayomali, C., Sutherland, S. and Finkelstein, F.O. (2008) The Challenge for the Caregiver of the Patient with Chronic Kidney Disease. Nephrology Dialysis Transplantation, 23, 3749-3751. http://dx.doi.org/10.1093/ndt/gfn577

[8] Caqueo-Urizar, A., Gutierrez-Maldonaldo, J. and Miranda-Castillo, C.(2009) Quality of Life in Caregivers of Patients with Schizophrenia: A Literature Review. Health and Quality of Life Outcomes, 7, 1-5.

[9] Rafiyah, S.I. (2011) Sutharangsee. Review: Burden on Family Caregivers Caring for Patients with Schizophrenia and Its Related Factors. Nurse Media Journal of Nursing, 29-41.

[10] Belasco, A., Barbosa, D., Bettencourt, A.R., et al. (2006) Quality of Life of Family Caregivers of Elderly Patients on Hemodialysis and Peritoneal Dialysis. American Journal of Kidney Diseases, 48, 955-963. http://dx.doi.org/10.1053/j.ajkd.2006.08.017

[11] Zarit, S.H., Todd, P.A. and Zarit, J.M. (1986) Subjective Burden of Husbands and Wives as Caregivers: A Longitudinal Study. Gerontologist, 26, 260-266. http://dx.doi.org/10.1093/geront/26.3.260

[12] Jones, S.L. (1996) The Association between Objective and Subjective Caregiver Burden. ARON Psychiatric Nursing, 10, 77-84. http://dx.doi.org/10.1016/S0883-9417(96)80070-7

[13] Belasco, A.G. and Sesso, R. (2002) Burden and Quality of Life of Caregivers for Hemodialysis Patients. American Journal of Kidney Diseases, 39, 805-812. http://dx.doi.org/10.1053/ajkd.2002.32001

[14] Wicks, M.N., Milstead, E.J. and Hathaway, D.K. (1997) Subjective Burden and Quality of Life End-Stage Renal Disease. ANNA Journal, 24, 527-540.

[15] Beanlands, H., Horsburgh, M.E., Fox, S., Howe, A., Locking-Cusolito, H., Pare, K. and Thrasher, C. (2005) Caregiving by Family and Friends of Adults Receiving Dialysis. Nephrology Nursing Journal, 32, 621-631.

[16] Suri, R.S., Larive, B., Garg, A.X., Hall, Y.N., Pierratos, A., Chertow, G.M., Gorodetskeya, I., Kliger, A.S. and FHN Study Group (2011) Burden on Caregivers as Perceived by Hemodialysis Patients in the Frequent Hemodialysis Network (FHN) Trials. Nephrology Dialysis Transplantation, 26, 2316-2322. http://dx.doi.org/10.1093/ndt/gfr007

[17] Rioux, J.P., Narayanan, R. and Chan, C.T. (2012) Caregiver Burden among Nocturnal Home Hemodialysis Patients. Hemodialysis International, 16, 214-219. http://dx.doi.org/10.1111/j.1542-4758.2011.00657.x

[18] Cameron, J.I., Franche, R.L., Cheung, A.M., et al. (2002) Lifestyle Interference and Emotional Distress in Family Caregivers of Advanced Cancer Patients. Cancer, 94, 521-527.

[19] Given, B. and Sherwood, P.R. (2006) Family Care for the Older Person with Cancer. Seminars in Oncology Nursing, 22, 43-50. http://dx.doi.org/10.1016/j.soncn.2005.10.006

[20] Arechabala, M.C., Catoni, M.I., Palma, E. and Barrios, S. (2011) Depression and Self-Perceived Burden of Care by Hemodialysis Patients and Their Caregivers. Revista Panamericana de Salud Pública, 30, 74-79. http://dx.doi.org/10.1590/S1020-49892011000700011

[21] Cossette, S. and Levesque, L. (1993) Caregiving Tasks as Predictors of Mental Health of Wife Caregivrs of Men with Chronic Obstructive Pulmonary Disease. Research in Nursing and Health, 16, 251-263. http://dx.doi.org/10.1002/nur.4770160404

[22] Kell-Card, G., Foxall, M.J. and Barron, C. (1993) Loneliness, Depression, and Social Support of Patients with COPD and Their Spouses. Public Health Nursing, 10, 245-251. http://dx.doi.org/10.1111/j.1525-1446.1993.tb00060.x

[23] Ferrans, C.E. and Powers, M.J. (1992) Psychometric Assessment of the Quality of Life Index. Research in Nursing and Health, 15, 29-38. http://dx.doi.org/10.1002/nur.4770150106

[24] Whitlatch, C.J., Zarit, S.H. and Von Eye, A. (1991) Efficacy of Interventions with Caregivers: A Reanalysis. Gerontology, 31, 9-14. http://dx.doi.org/10.1093/geront/31.1.9 